\title{
De vermogensscheidingsregeling voor beleggingsinstellingen als (alternatief) model voor de bescherming van derivatenbeleggers
}

\author{
$M r . E . W . K u i j p e r^{*}$
}

\section{Inleiding}

Deelnemen in een beleggingsfonds en handelen in (financiële) derivaten zijn twee verschillende manieren van beleggen. Toch loopt zowel de deelnemer in een beleggingsfonds als de belegger die via een tussenpersoon handelt in derivaten eenzelfde risico, namelijk het risico dat iemand die niets met 'zijn' beleggingen van doen heeft daarop verhaal neemt. ${ }^{1}$ Het verhaalsrisico van de belegger die deelneemt in een fonds voor gemene rekening wordt gemitigeerd door een goederenrechtelijke vermogensscheidingsregeling, opgenomen in de Wet op het financieel toezicht (Wft). Voor derivatenbeleggers is de minister daarentegen nog zoekende naar een mechanisme dat hun rechten adequaat beschermt. Al in 2007 heeft de minister daartoe voorgesteld de Wet giraal effectenverkeer (Wge) aan te passen. ${ }^{2}$ Vanwege kritiek op de praktische haalbaarheid is het destijds bij een voorstel gebleven. Inmiddels is een nieuw voorstel gepubliceerd waarin er opnieuw voor wordt gekozen een beschermingsregeling op te nemen in de Wge (hierna: Ontwerpregeling). ${ }^{3}$ In 2007 heeft Grundmann-van de Krol echter de vraag opgeworpen waarom de bescherming van de rechten van derivatenbeleggers niet wordt geregeld in de $\mathrm{Wft}$ en wel op soortgelijke manier als de bescherming voor de deelnemers in een beleggingsfonds. ${ }^{4}$

Het idee van Grundmann-van de Krol is nooit nader uitgewerkt. Die uitdaging neem ik in deze bijdrage voor mijn rekening. Ik beargumenteer dat een regeling in de Wft, soortgelijk aan de (rang)regeling voor beleggingsinstellingen, uitkomst kan bieden voor de bescherming van derivatenbeleggers en kan

Mr. E.W. Kuijper is als promovenda verbonden aan het Molengraaff Instituut voor Privaatrecht (Universiteit Utrecht). Daarvoor was zij werkzaam als bedrijfsjurist bij KAS BANK te Amsterdam.

1. Dit verhaalsrisico wordt ook wel intermediary risk genoemd, zie bijv. Asser/Bartels \& Van Mierlo 3-IV 2013/579.

2. Ontwerpwetsvoorstel wijziging van de Wet giraal effectenverkeer.

3. Ontwerpwetsvoorstel wijziging van de Wet op het financieel toezicht en enige andere wetten op het terrein van de financiële markten 2016 (Wijzigingswet financiële markten 2016; het Ontwerpwetsvoorstel).

4. C.M. Grundmann-van de Krol, Wetsvoorstel implementatie MiFID in de Wft, Ondernemingsrecht 2007, afl. 10-11, p. 423. dienen als mogelijk alternatief voor de Ontwerpregeling. Ter begripsvorming schets ik daartoe eerst de achtergrond van het probleem dat zich voordoet bij beide manieren van beleggen (par. 2) en vergelijk de vereiste beschermingsniveaus voor beide categorieën beleggers (par. 3). Voorts beschrijf ik de regeling voor beleggingsinstellingen per onderdeel en toets of het systeem kan dienen als beschermingsmechanisme voor derivatenbeleggers (par. 4). Ik sluit af met een conclusie (par. 5).

\section{Het verhaalsrisico van de deelnemer in een} beleggingsfonds en de derivatenbelegger

Het idee van Grundmann-van de Krol is zo gek nog niet, want het probleem dat speelt bij het beleggingsfonds, specifiek het fonds voor gemene rekening, heeft eenzelfde oorzaak als het probleem dat speelt bij de bemiddeling in derivaten. Het verhaalsrisico ontstaat doordat een ander dan de belanghebbende de rechthebbende is. Omdat een fonds voor gemene rekening geen rechtspersoon is, maar een samenwerkingsvorm sui generis tussen de deelnemers, een beheerder en een aparte entiteit (al dan niet de bewaarder van het fonds), ${ }^{5}$ wordt het fondsvermogen, bestaande uit de inleg van de deelnemers en financiële instrumenten, ondergebracht bij de aparte entiteit, die daarvan fungeert als rechthebbende 'ten titel van beheer'. ${ }^{6}$ Hoewel hierdoor wordt voorkomen dat schuldeisers van de beheerder of van de afzonderlijke deelnemers zich kunnen verhalen op het fondsvermogen, is niet uitgesloten dat (privé)crediteuren van de aparte entiteit haar vermogen, waarvan het fondsvermogen deel uitmaakt, aanspreken.

5. Zie D.F.M.M. Zaman \& M.S. Koppert-van Beek, De kwalificatie van het fonds voor gemene rekening, Ondernemingsrecht 2008/109, W.A.K. Rank \& B. Bierman, Aangaan van verplichtingen voor rekening van een FGR: aansprakelijkheid en verhaal, TvFR 2008, afl. 9, p. 299 en C.J. Groffen, De positie van deelnemers in een beleggingsfonds, V\&O 1995, afl. 10 , p. 110.

6. Zie Kamerstukken II 2002/03, 28998, 3, p. 6 (MvT), J.W.P.M. van der Velden, Beleggingsfondsen naar burgerlijk recht (diss. Nijmegen), Deventer: Kluwer 2008, p. 129 en Groffen 1995, p. 111. De entiteit houdt het fondsvermogen aan in eigen naam ten behoeve van de gezamenlijke deelnemers. 
Hoe ziet het verhaalsrisico eruit dat speelt bij de dienstverlening in derivaten? Beleggers kunnen derivaten onderhands sluiten met een tegenpartij (over-the-counter, OTC) of geanonimiseerd via een georganiseerd handelsplatform zoals de beurs. In het navolgende ga ik in op laatstgenoemde manier van verhandeling. Opties en futures zijn twee basisvormen van derivaten die, met uiteenlopende financiële onderliggende waarden, zoals aandelen, een index of een valuta, worden verhandeld via de beurs.

Via de beurs kan ik bijvoorbeeld een contract aangaan om op een toekomstig tijdstip (de 'expiratiedatum') ${ }^{7}$ honderd aandelen Heineken te kopen voor $€ 55$ per aandeel. Stel dat op de expiratiedatum de koers van het aandeel is gedaald naar $€ 53$. Uit hoofde van het futurecontract ben ik verplicht de aandelen te kopen of, bij afwikkeling in contanten, het verschil tussen de afgesproken prijs en de marktprijs te betalen. In dit geval had ik beter een (call)optie kunnen 'kopen'. Dit contract had mij het recht gegeven, en dus niet de verplichting, om gedurende de looptijd van het contract, of aan het einde daarvan, de aandelen te kopen tegen de afgesproken prijs. Voor het optierecht had ik als 'houder' een premie moeten betalen aan mijn wederpartij, de 'schrijver' van de optie. De schrijver had dan de aandelen aan mij moeten verkopen, of het prijsverschil moeten betalen, indien ik zou hebben besloten de optie uit te oefenen (wat ik in dit geval niet had gedaan). Belangrijk is dat een derivatencontract een wederkerige overeenkomst is, die een (toekomstig) recht inhoudt op levering van een bepaalde hoeveelheid effecten of ontvangst van een geldsom, dan wel het spiegelbeeld, een verplichting tot levering van een bepaalde hoeveelheid effecten of betaling van een geldsom.

De transactie komt als volgt tot stand. De belegger legt een koop- of verkooporder in bij een tussenpersoon, meestal een bank of beleggingsonderneming, ${ }^{8}$ die is aangesloten bij de beurs. ${ }^{9}$ De tussenpersoon voert de order uit op de beurs, waar de order via het handelssysteem wordt gematcht met een tegenliggende order. Beursverhandelde derivaten worden gebruikelijk centraal gecleard door een clearingorganisatie die de verplichtingen aan beide zijden van de transactie over-

7. Bij georganiseerd verhandelde derivaten is dat meestal de derde vrijdag van de maand.

8. Het uitvoeren van orders in financiële instrumenten, waaronder derivaten, is een beleggingsdienst in de zin van de MiFID en art. 1:1 Wft. Alleen banken of andere rechtspersonen (beleggingsondernemingen) die over de benodigde vergunning beschikken, mogen deze dienst verlenen.

9. De belegger voldoet zelf niet aan de voorwaarden voor aansluiting bij het handelssysteem van de beurs. neemt ${ }^{10}$ en de nakoming daarvan garandeert. ${ }^{11}$ De transactie wordt doorgeleid naar de clearingorganisatie, waarna een derivatencontract tot stand komt tussen enerzijds de clearingorganisatie en de koperszijde en anderzijds de clearingorganisatie en de verkoperszijde. ${ }^{12}$ Als de tussenpersoon naast aansluiting bij de beurs tevens aansluiting heeft bij het clearingsysteem (als 'clearing member'), ${ }^{13}$ gaat de tussenpersoon zelf het derivatencontract aan met de clearingorganisatie en houdt het (toekomstige) recht dan wel de verplichting die daaruit voortvloeit (de 'positie') ${ }^{14}$ aan voor rekening en risico van de cliënt. ${ }^{15}$ Laatstgenoemde heeft een recht dan wel verplichting jegens de tussenpersoon, die qua inhoud correspondeert met de positie die de tussenpersoon inneemt voor rekening van de cliënt bij de clearingorganisatie (de 'cliëntenpositie'). ${ }^{16} \mathrm{Dit}$ is gedocumenteerd in een dienstverleningsovereenkomst tussen de cliënt en de tussenpersoon. Vloeit uit het derivatencontract een (toekomstig) recht voort, dan kunnen in beginsel, in lijn met het uitgangspunt uit art. 3:276 van het Burgerlijk Wetboek (BW), alle schuldeisers van de tussenpersoon zich daarop verhalen. Dit is duidelijk geworden toen kredietinstelling Van der Hoop failleerde eind 2005. Cliënten voor wier rekening Van der

10. Dit geschiedt via novatie of een open offer-structuur, zie B.J.A. Zebregs, Effecten- en derivatenclearing, Amsterdam: NIBE-SVV 2013, p. 36-51 en L.J. Silverentand \& P. Heemskerk, Clearing: kern- en knelpunten, in: S.E. Bartels, A.J. Verdaas \& R.J. van der Weijden (red.), Effecten en vermogensrecht, Deventer: Kluwer 2011, p. 242 e.v.

11. Centrale clearing is marktgebruik bij georganiseerd verhandelde derivaten en onder de EMIR verplicht voor bepaalde OTC-derivaten. De term 'clearing' heeft een verschillende betekenis naargelang marktpraktijken en clearingstructuren uiteenlopen. Art. 2 lid 3 EMIR definieert clearing als 'het proces waarbij een CTP posities vaststelt, inclusief het berekenen van nettoverplichtingen, en ervoor zorgt dat financiële instrumenten, contanten of beide beschikbaar zijn om de uit deze posities voortkomende risicopositie zeker te stellen'. Clearing is dus een verzamelnaam voor bepaalde administratieve processen die plaatsvinden na de totstandkoming van een derivatencontract, maar voor de afwikkeling daarvan, vgl. Silverentand \& Heemskerk 2011, p. 239.

12. De clearingorganisatie absorbeert het tegenpartijrisico. $\mathrm{Zij}$ hanteert verschillende technieken om dit risico te beheersen, waaronder het stellen van voorwaarden voor aansluiting bij het clearingsysteem en het verlangen van zekerheden ter afdekking van de verplichtingen uit hoofde van derivatencontracten.

13. De tussenpersoon die de order uitvoert op de beurs hoeft geen clearing member te zijn. In dat geval maakt de tussenpersoon gebruik van de clearingdiensten van een clearing member om de derivatencontracten voor zijn rekening tot stand te brengen. Er is sprake van een verlengde transactieketen.

14. De waarde van de positie op een bepaald moment wordt economisch weergegeven in een transactie- of positierekening.

15. De relatie tussen de cliënt en zijn tussenpersoon kwalificeert als lastgeving in eigen naam ex art. 7:420 BW, een vorm van middellijke vertegenwoordiging. In een verlengde transactieketen handelt de tussenpersoon als onderlastgever van de cliënt en de clearing member als onderlasthebber, zie Zebregs 2013, p. 71 en L.D. van Setten, De commissionair in effecten (diss. Utrecht), Deventer: Kluwer 1998, p. 308.

16. Directe verkrijging door de cliënt van de vorderingen, of de baten die voortvloeien uit de afwikkeling van het derivaat, op grond van art. 3:110 BW gaat niet op. Het betreft immers vermogensrechten en geen zaken die door middel van bezitsverschaffing kunnen worden geleverd, zie HR 23 september 1994, NJ 1996/461 (Kas-Associatie/Drying Corporation). De rechten of baten gaan pas deel uitmaken van het vermogen van de cliënt na doorlevering door de tussenpersoon. 


\section{Maandblad \\ Vermogensrecht}

Hoop orders in opties en futures had uitgevoerd, ${ }^{17}$ kregen bericht van de curatoren dat de rechten en verplichtingen die voortvloeiden uit de met de orders corresponderende derivatencontracten ${ }^{18}$ niet waren afgescheiden van het vermogen van Van der Hoop. ${ }^{19}$ Voor zover de positie een vordering representeerde, kwalificeerde de vordering van de cliënt op Van der Hoop als een concurrente vordering. Een beroep van cliënten op overgang van de rechten van Van der Hoop jegens diens clearing member uit hoofde van art. 7:420 lid $1 \mathrm{BW}$ slaagde niet omdat de clearing member een dergelijk beroep contractueel had uitgesloten.

\section{Welk beschermingsniveau?}

Voor deelnemers in gereguleerde beleggingsinstellingen is het verhaalsrisico beperkt door een vermogensscheidingsregeling in de $\mathrm{Wft}$, waarover meer in paragraaf 4 . Doel van die regeling is 'het zodanig afscheiden van het vermogen van het beleggingsfonds dat de gevolgen van faillissement van een van de betrokkenen - de beheerder, de bewaarder of de deelnemers zo veel mogelijk worden beperkt'. ${ }^{20}$ Het fondsvermogen dient ten minste te worden afgeschermd van verhaal door schuldeisers die daarmee niets van doen hebben. Beperking van de gevolgen van faillissement houdt ook in dat het fondsvermogen bij faillissement van de aparte entiteit kan worden ondergebracht bij een andere entiteit, die de taak van rechthebbende overneemt.

Europese regelgeving schrijft voor welke bescherming voor derivatenbeleggers moet worden gerealiseerd. Zo vereist de Markets in Financial Instruments Directive 2014/65 (MiFID II) dat een (bank-)beleggingsonderneming die financiële instrumenten aanhoudt voor cliënten adequate regelingen treft ter 'vrijwaring' van de 'eigendomsrechten' van de cliënt, met name bij insolventie van de (bank-)beleggingsonderneming. ${ }^{21}$ Vrijwaring betekent hier het beschermen van de rechten die toekomen aan de cliënt tegen uitwinning door schuldeisers van de (bank-)beleggingsonderneming. Omdat, zoals hierboven is uitgelegd, het eigenlijke financiële instrument tot stand komt tussen de tussenpersoon en de clearingorganisatie en de cliënt enkel een daarvan afgeleid recht heeft, dienen de derivatenposities die de tussenpersoon inneemt bij de clearingorganisatie voor rekening en risico van de cliënt onderwerp van de bescherming te zijn. Naast MiFID II bevat de Euro-

17. In deze casus was sprake van een verlengde transactieketen. Voor de clearing van derivaten had Van der Hoop een clearing member ingeschakeld.

18. In dit geval waren dat de rechten en verplichtingen die Van der Hoop aanhield uit hoofde van de dienstverleningsovereenkomst jegens diens clearing member en die correspondeerden met de derivatencontracten die de clearing member voor Van der Hoop tot stand had gebracht in verband met de orders van cliënten.

19. Brief van Houthoff aan de houders van opties en futures, 1 februari 2006, p. 1.

20. Kamerstukken II 2002/03, 28998, 3, p. 17 (MvT). De toelichting hoort bij de voorloper van de huidige regeling die was opgenomen in art. 5, 9 en $16 \mathrm{a} \mathrm{Wtb}$ (oud).

21. Art. 16 lid 8 MiFID II. Art. 13 lid 7 MiFID (2004/39), de voorloper van art. 16 lid $8 \mathrm{MiFID}$ II, is letterlijk overgenomen in art. 4:87 Wft. De derivaten kwalificeren als financieel instrument in de zin van bijlage I, deel C MiFID II (en art. 1:1 Wft). pean Market Infrastructure Regulation 648/2012 (EMIR) bepalingen die bescherming beogen van beleggers die handelen in derivaten die centraal worden gecleard. ${ }^{22}$ Clearingorganisaties dienen procedures in werking te hebben op grond waarvan zij cliëntenposities, inclusief de bijbehorende zekerheden, bij faillissement van een clearing member kunnen overdragen aan een andere clearing member. ${ }^{23}$ Omdat posities die een tussenpersoon aanhoudt bij een clearingorganisatie voor rekening van cliënten naar Nederlands recht onder het faillissementsbeslag vallen, kan de curator van een Nederlandse clearing member overdracht van posities door de clearingorganisatie frustreren indien hij dit niet in het belang acht van de boedel of van mening is dat andere crediteuren daardoor worden benadeeld. ${ }^{24}$

\section{Een soortgelijke vermogensscheidingsregeling als uitkomst?}

De bescherming van de belegger in een fonds voor gemene rekening is vastgelegd in art. 4:37 $\mathrm{j} \mathrm{Wft}$. De regeling bestaat uit drie onderdelen, te weten een eis tot het onderbrengen van de activa van het fonds bij een aparte entiteit, een rangregeling en een afgescheiden vermogen. Omdat elk onderdeel een bepaalde mate van bescherming biedt, toets ik per onderdeel of het systeem geschikt is als beschermingsmechanisme voor derivatenbeleggers.

\subsection{Aparte entiteit als rechthebbende}

Het eerste onderdeel van de regeling vereist dat 'de eigendom van de activa van het beleggingsfonds wordt gehouden door een entiteit met als enig statutair doel het houden van de juridische eigendom van de activa van een of meer beleggings-

22. Dit zijn naast georganiseerd verhandelde derivaten tevens OTC-derivaten die clearingplichtig zijn onder de EMIR.

23. Art. 48 lid $4 \mathrm{t} / \mathrm{m} 6$ EMIR. Dit vereiste geldt niet alleen voor cliëntenposities, maar ook voor de bijbehorende zekerheden. Opmerking verdient dat de bescherming van de derivatenbelegger niet compleet is zonder dat ook een regeling wordt getroffen voor de overdracht of retournering van zekerheden die zijn gesteld in verband met de cliëntenposities. Het reikt te ver om daar in deze bijdrage op in te gaan. Ik merk slechts op dat het stellen van zekerheden, hoewel voorwaarde voor dienstverlening, een zelfstandige verplichting is die losstaat van het derivatencontract, waardoor voor de cliëntenposities en de zekerheidsstelling een aparte regeling kan worden getroffen.

24. Tenzij de clearingorganisatie is angewezen als 'systeem' in de zin van de Finaliteitsrichtlijn $98 / 26$, zie ook art. 212e Fw, en het recht dat van toepassing is op dat systeem bepaalt dat de curator overdracht niet mag frustreren. Is bijvoorbeeld Engels recht van toepassing op het systeem, dan bepaalt dit kort gezegd dat de procedures van de clearingorganisatie voorrang hebben boven het algemene faillissementsrecht bij insolventie van een deelnemer, zie S. 159 UK Companies Act 1989. Tevens, om te voorkomen dat nationale wetgeving overdracht van posities kan frustreren, dienen volgens overweging 64 Preambule EMIR de eisen inzake overdracht van posities voorrang te hebben boven tegenstrijdige nationale wetten, regels en bestuursrechtelijke bepalingen die clearingorganisaties verhinderen de eisen na te leven. De vraag is echter wat de rechtskracht is van een dergelijke overweging in de preambule. 
fondsen $(\ldots)^{\prime 25}$ om te voorkomen dat schuldeisers van de beheerder of de afzonderlijke deelnemers zich daarop verhalen.

Het onderbrengen van cliëntenposities bij een aparte entiteit zou geen toegevoegde waarde hebben voor derivatenbeleggers. De redenen voor het aanwijzen van een aparte entiteit als rechthebbende bij het beleggingsfonds ontbreken bij derivatenbemiddeling. Cliëntenposities worden niet aangehouden voor meerdere beleggers gezamenlijk, maar voor individuele cliënten. ${ }^{26}$ De posities hoeven daarom niet te worden beschermd tegen verhaal door crediteuren van de afzonderlijke beleggers. Voorts is er geen aparte beheerder en kan in het algemeen ook niet worden gesproken van 'beheer'. De tussenpersoon houdt de rechten en verplichtingen uit hoofde van de derivatencontracten aan als onderdeel van de dienstverlening en verricht de bijkomende taken. Hij vertegenwoordigt de cliënt in beginsel niet bij het nemen van de beleggingsbeslissing. ${ }^{27}$ De enige bedreiging vormen de crediteuren van de tussenpersoon. ${ }^{28}$

\subsection{Rangregeling}

Het tweede onderdeel mitigeert het risico dat anderen dan fondscrediteuren verhaal nemen op het vermogen dat de aparte entiteit aanhoudt inzake het beleggingsfonds via een rang re ge ling. Kort gezegd bepaalt art. 4:37j lid $5 \mathrm{Wft}$ dat het vermogen van een beleggingsinstelling uitsluitend dient tot voldoening van vorderingen van fondscrediteuren. Pas als vaststaat dat alle (toekomstige) vorderingen van fondscrediteuren kunnen worden voldaan, kunnen andere vorderingen op het fondsvermogen worden verhaald. ${ }^{29}$

Langs dezelfde lijn kan ten behoeve van derivatenbeleggers een rangregeling worden vormgegeven op grond waarvan cliënten-

25. Art. 4:37j lid $1 \mathrm{Wft}$. Hoewel het gebruik van de term 'activa' doet vermoeden dat de aparte entiteit alleen goederen onder zich heeft, blijkt uit de wet en de parlementaire geschiedenis dat de aparte entiteit ook de verplichtingen inzake het fonds draagt, zie Van der Velden 2008, p. 130-134.

26. Het fondsvermogen bestaat uit gelden en financiële instrumenten (dit kunnen ook derivaten zijn). Koopt de belegger een deelnemingsrecht, dan deelt hij voor een bepaald breukdeel in de waarde van het gehele fondsvermogen. Er kunnen geen gelden of financiële instrumenten worden toegewezen aan een bepaalde deelnemer. Derivatenposities kunnen daarentegen aan de hand van een ordernummer worden gekoppeld aan de order van een individuele cliënt door de tussenpersoon. Orders in derivaten van individuele cliënten worden, in tegenstelling tot orders in effecten, in beginsel niet verrekend, zie Van Setten 1998, p. 312.

27. Dit is slechts anders indien de tussenpersoon de dienst vermogensbeheer verleent aan de cliënt. Doorgaans voert de tussenpersoon de orders echter uit op basis van een execution-only- of beleggingsadviesrelatie, zie over die relaties M. van Luyn \& C.E. du Perron, Effecten van de zorgplicht, Deventer: Kluwer 2004, p. 78 en S.B van Baalen, Zorgplichten in de effectenhandel (diss. Groningen), Deventer: Kluwer 2006, p. 53-91.

28. Het aanwijzen van een aparte entiteit als rechthebbende van cliëntenposities stuit bovendien op praktische problemen. Om als rechthebbende te kunnen optreden, zou de entiteit de derivatencontracten moeten sluiten met de clearingorganisatie. Tenzij de entiteit een bank is, zou de entiteit voor die activiteit een vergunning behoeven op grond van art. 2:4 Wft en moeten voldoen aan bijkomende vergunningseisen.

29. Art. 4:37j lid $7 \mathrm{Wft}$. posities en de baten die voortvloeien uit de afwikkeling daarvan exclusief verhaalsobject worden van schuldeisers die een vordering hebben op één of meer van die posities. ${ }^{30}$ Worden de posities bij faillissement van de tussenpersoon (vervroegd) gesloten, dan hebben alleen deze schuldeisers (de cliënten) een vordering op de baten. Bovendien kan de rangregeling bijdragen aan de overdracht van cliëntenposities. Als wettelijk is bepaald dat cliëntenposities uitsluitend dienen tot voldoening van vorderingen van bepaalde schuldeisers, kan de curator moeilijk tegenwerpen dat overdracht van posities de paritas creditorum doorbreekt of niet in het belang is van de boedel. Algemene crediteuren worden immers niet benadeeld door de overdracht omdat de posities voor hen al niet vatbaar waren voor verhaal.

\subsection{Afgescheiden vermogen}

Per 2014 omvat art. 4:37j lid $5 \mathrm{Wft}$ een derde onderdeel, dat bepaalt dat het vermogen van een beleggingsinstelling een 'afgescheiden vermogen' is. Bij nadere bestudering van de toelichting blijkt dat de passage inhoudelijk weinig toevoegt aan de bescherming die de rangregeling reeds realiseert. Het afgescheiden vermogen is geen rechtsfiguur, waardoor het rechtsgevolg dat men daaraan kan verbinden, afhangt van de definitie die de wetgever de term meegeeft. De rechtsliteratuur verstaat onder een afgescheiden vermogen een deel van het vermogen van één rechtssubject waarop uitsluitend schuldeisers zich kunnen verhalen wier vorderingen betrekking hebben op dat vermogen (verhaalsexclusiviteit). ${ }^{31}$ De toelichting sluit daar niet bij aan. Volstaan wordt met de opmerking dat de rangregeling de facto reeds leidt tot een afgescheiden vermogen $^{32}$ en dat de bepaling inzake het afgescheiden vermogen slechts is opgenomen ter verduidelijking. ${ }^{33}$ Het afgescheiden vermogen heeft geen inhoud. Feitelijk wordt de bescherming van fondsdeelnemers dus gerealiseerd door de rangregeling en

30. Een wettelijke uitzondering op het uitgangspunt uit art. 3:276 BW.

31. Zie over de kenmerken van een afgescheiden vermogen o.a. N.E.D. Faber, Eigendom ten titel van beheer, kwaliteitsrekening en afgescheiden vermogen, in: D.J. Hayton, S.C.J.J. Kortmann, A.J.M. Nuytinck e.a. (red.), Vertrouwd met de trust, trust and trust-like arrangements, Deventer: W.E.J. Tjeenk Willink 1996, p. 197-198, T.H.D. Struycken, De numerus clausus in het goederenrecht (diss. Nijmegen), Kluwer: Deventer 2007, p. 540-542, A. Steneker, Kwaliteitsrekening en afgescheiden vermogen (diss. Nijmegen), Kluwer: Deventer 2005, p. 112-142 en Van der Velden 2008, p. 147.

32. De minister verwijst naar een discussie in de rechtsliteratuur over de vraag of het fondsvermogen op grond van de rangregeling een afgescheiden vermogen is. Alleen uitgaande van de feitelijke verhaalsmogelijkheden wordt deze vraag positief beantwoord, zie Van der Velden 2008, p. 145-149 en Struycken 2007, p. 541-542.

33. Kamerstukken II 2012/13, 33632, 3, p. 81 (MvT). Voor de toepassing van de rangregeling binnen het nationale recht heeft de aanpassing geen gevolgen. Het nut van het aanwijzen van het vermogen van de beleggingsinstelling als afgescheiden vermogen zoekt de minister in de internationale context. 


\section{Maandblad \\ Vermogensrecht}

niet door het afgescheiden vermogen, ${ }^{34}$ wat het gebruik van de term verwarrend maakt. ${ }^{35}$ Enerzijds wijst de wet het vermogen van een beleggingsinstelling aan als een afgescheiden vermogen, maar anderzijds voldoet het niet aan de kenmerken.

Interessant is te bezien of een werkelijk afgescheiden vermogen uitkomst kan bieden als beschermingsmechanisme voor derivatenbeleggers. Op grond van de Ontwerpregeling heeft een tussenpersoon ${ }^{36}$ een afgescheiden vermogen (het derivatenvermogen) waartoe alle derivatenposities behoren die hij is aangegaan met derden voor rekening en risico van cliënten. ${ }^{37}$ De minister geeft het afgescheiden vermogen handen en voeten door aan te geven dat het derivatenvermogen 'in geval van faillissement buiten de boedel blijft' 38 en dat 'de bestanddelen van dit afgescheiden vermogen zijn gereserveerd voor het voldoen van vorderingen uit hoofde van de daarmee samenhangende derivatenposities van cliënten'. ${ }^{39}$ In tegenstelling tot het fondsvermogen bezit het derivatenvermogen alle eigenschappen die kenmerkend zijn voor het afgescheiden vermogen en kan het zowel verhaalsbescherming bieden als een vermogensrechtelijke basis voor de overdracht van cliëntenposities.

Desondanks kan de regeling leiden tot verwarring. Verwarring ontstaat waar de Ontwerpregeling de curator de verantwoordelijkheid geeft over het 'beheer' van het derivatenvermogen, ${ }^{40}$ terwijl de Faillissementswet (Fw) niet van toepassing is. Voorts is verwarrend dat de regeling wordt opgenomen in de Wge, een wet die naast de girale afwikkeling van effectentransacties de bescherming van de effectenbezitter tegen faillissementsrisico regelt. Derivaten zijn geen effecten in de zin van de Wge en de Ontwerpregeling brengt daarin geen verandering. Een beschermingsregeling voor derivatenbeleggers, en al

34. Bovendien wordt die bescherming voor deelnemers in een beleggingsmaatschappij reeds gerealiseerd door Boek $2 \mathrm{BW}$ en ten aanzien van het vermogen van personenvennootschappen is in de rechtspraak erkend dat het een afgescheiden vermogen betreft; zie voor de commanditaire vennootschap HR 14 maart 2003, NJ 2003/327 m.nt. Maeijer (Hovuma/ Spreeuwenberg) en Hof Arnhem-Leeuwarden 1 april 2014, JIN 2014/111 m.nt. F. Oostlander, voor de (openbare) maatschap HR 15 maart 2013, RO 2013/30 (x/Schepen Onderlinge Nederland U.A.) en voor de vennootschap onder firma Asser/Maeijer 5-V 1995/173 e.v.

35. Het vermogen van de beleggingsinstelling wordt immers aangemerkt als afgescheiden vermogen, maar voldoet niet aan de kenmerken die daaraan in de rechtsliteratuur worden verbonden.

36. Art. $49 \mathrm{f}$ onderdeel g Ontwerpwetsvoorstel. Een tussenpersoon kan zijn een bank, beleggingsonderneming of clearinginstelling.

37. Art. $49 \mathrm{f}$ onderdeel f Ontwerpwetsvoorstel.

38. MvT bij het Ontwerpwetsvoorstel, p. 8. De bedoeling is dat de Fw niet van toepassing is op het derivatenvermogen.

39. MvT bij het Ontwerpwetsvoorstel, p. 6. Opgemerkt zij dat de definities in de Ontwerpregeling zijn afgestemd op een handelsmodel waarbij de tussenpersoon niet (alleen) optreedt als lasthebber, maar (tevens) als tegenpartij van de cliënt, wat voorkomt in de OTC-markt. Tussen de cliënt en de tussenpersoon komt dan een derivatencontract (derivatenpositie) tot stand. De regeling sluit niet aan bij de handel in derivaten, die uitsluitend geschiedt op basis van lastgeving, zoals de beurshandel. De minister doet een poging dit te lijmen in de toelichting op p. 41. Onder 'de daarmee samenhangende derivatenposities van cliënten' kan gemakshalve worden verstaan de vorderingen van de cliënt uit hoofde van de dienstverleningsovereenkomst met de tussenpersoon.

40. Art. $49 \mathrm{~h}$ lid 1 Ontwerpwetsvoorstel. helemaal een die een 'wezenlijk andere vorm van vermogensscheiding' ${ }^{41}$ betreft dan het Wge-systeem, heeft weinig te zoeken in de Wge. ${ }^{42}$

Voorgaande doet de vraag rijzen of de gewenste bescherming niet beter op andere wijze kan worden gerealiseerd dan via een afgescheiden vermogen. Zoals paragraaf 4.2 uitwijst, biedt een rangregeling een mogelijk alternatief. De regeling kan zodanig worden vormgegeven dat zij feitelijk niet onderdoet voor een afgescheiden vermogen. Nadeel is dat een rangregeling niet verhindert dat bij faillissement van de tussenpersoon de Fw van toepassing is, wat mogelijk praktische complicaties meebrengt voor de overdracht van posities na faillietverklaring. Dit kan worden ondervangen door een uitzonderingsbepaling in de $\mathrm{Fw}$, op grond waarvan het faillissementsrecht niet in de weg staat aan overdracht van cliëntenposities door een clearingorganisatie. De minister geeft aan dat zowel Duitsland als Engeland en Frankrijk werken met een dergelijke uitzonderingsbepaling om de EMIR-doeleinden te faciliteren. ${ }^{43}$

Bij voorkeur wordt de regeling opgenomen in de Wft. Deze wet leent zich voor regeling van de bescherming van derivatenbeleggers omdat daarin art. 13 lid $7 \mathrm{MiFID}$ is geïmplementeerd en tevens eisen worden gesteld aan de organisatie en dienstverlening van banken, beleggingsondernemingen en clearinginstellingen. Bovendien is de vermogensscheidingsregeling voor beleggingsinstellingen ook te vinden in de Wft. Een vermogensrechtelijke regeling in een wet met een uitgesproken publiekrechtelijk karakter is dus geen noviteit.

\section{Conclusie}

Hoewel ik niet betwijfel dat een afgescheiden vermogen, zoals voorgesteld in de Ontwerpregeling, de gewenste bescherming voor derivatenbeleggers kan realiseren, blijft het afgescheiden vermogen - bij gebrek aan een algemene wettelijke regeling een onduidelijke figuur die tot verwarring kan leiden. Mocht de Ontwerpregeling, om voornoemde of andere reden, niet worden omarmd, dan kan een rangregeling, soortgelijk aan de vermogensscheidingsregeling voor beleggingsinstellingen, eventueel gecompleteerd door een uitzonderingsbepaling in de Fw, een alternatieve manier van bescherming bieden. Een dergelijke regeling kan het beste worden opgenomen in de Wft, precies zoals Grundmann-van de Krol zeven jaar geleden heeft geopperd.

41. MvT bij het Ontwerpwetsvoorstel, p. 6.

42. De Wge-bescherming berust op een bewindachtige constructie, waarin de effectenbezitter deelgerechtigd is in een (effecten)gemeenschap, beheerd door de tussenpersoon. In de Ontwerpregeling is de tussenpersoon juist rechthebbende van het derivatenvermogen.

43. MvT bij het Ontwerpwetsvoorstel, p. 8. 